\title{
Parenting style: an Inter-Generational Study
}

\author{
Bushra Faraz $^{1 *}$, Syeda Mamta Jinnat Adam², M.G. Shahnawaz ${ }^{3}$
}

\section{ABSTRACT}

The present study aimed at exploring how parenting styles have changed across generations in the Indian context. This study was carried out by mixed method (using both quantitative and qualitative measures). For quantitative analysis, the sample comprised of 100 family units residing in Guawhati, Assam which consists of two generation of mothers of the age group 50 years and above and, the second generation of mothers was of 30 years and above. For qualitative analysis, 5 family units were taken, viz 5 mothers of first generation and 5 mothers of second generation were participated. For quantitative analysis, Parental Authority Questionnaire (Buri, 1991) was used for measuring Baumrind's (1971) authoritarian, authoritative and permissive style of parenting. For qualitative analysis, IPA (Interpretative phenomenological approach) was used. Results showed that parenting style passes from generation to generation to some extent. Both generations of parents used authoritative parenting styles more than the other two styles. Four major themes have emerged in the qualitative analysis. Qualitative results showed that parents of new generations have given more freedom to their children; however, reasoning is used more by the older generation. Punishment of any kind is more prevalent among older generation parents than the new generation of parents.

\section{Keywords: Authoritative Parenting style, Authoritarian Parenting style, Permissive Parenting} style

A parenting style is a psychological construct representing standard strategies that parents use in child rearing. Parenting style basically depends upon various combinations of strategies: How much time a parent spends with their children? How strictly the parent imposed and creates certain norms in order to maintain their children within disciplined surroundings? How much the parent communicates with their children? To what extent the parent communicate with their children? All these strategies in the nutshell define the parenting style. Baumrind (1967) has worked extensively in this area and her theory has shaped the discourse on parenting styles. She used some of the concerns mentioned above in developing her model. She found four basic elements that could help shape successful parenting: responsiveness vs. unresponsiveness and

\footnotetext{
${ }^{1}$ Research Scholar, Department of Psychology, Jamia Millia Islamia

${ }^{2}$ Post graduate student, Department of Psychology, Jamia Millia Islamia

${ }^{3}$ Professor, Department of Psychology, Jamia Millia Islamia

*Corresponding Author

(C) 2015 I B Faraz, M Syeda, M Shahnawaz; licensee IJIP. This is an Open Access Research distributed under the terms of the Creative Commons Attribution License (http://creativecommons.org/licenses/by/2.0), which permits unrestricted use, distribution, and reproduction in any Medium, provided the original work is properly cited.
} 


\section{Parenting style: an Inter-Generational Study}

demanding vs. undemanding. Based on these dimensions, she suggested that the majority of parents display one of three different parenting styles: Authoritative parenting, authoritarian parenting and permissive parenting. Further research by Maccoby and Martin also suggested the addition of a fourth parenting style, uninvolved Parenting style (1983).

According to Baumrind, (1967) Authoritarian parents "are obedience- and status-oriented, and expect their orders to be obeyed without explanation." Authoritative parents "direct the child's activities in a rational, issue-oriented manner, use reasoning, and try to understand his/her objections when he/she refuses to conform. Permissive parents "behave in an accepting, affirmative and non-punitive way towards the child's wishes and actions". Different outcomes have been found with respect to these three parenting styles (Bhargava and Aurora, 2001; Berger, 2001; Collins et al. 2000; Steinberg, 1996)

According to Bowman (2007) the uninvolved parenting style is often called the indifferent parenting style or dismissive parenting. In this parenting style, parents are unresponsive to children. They are also undemanding, making this the exact opposite of active parenting. This type of parenting style borders on neglectful parenting (Luyckx et al., 2011; Adalbjarnardottir \&; Hafsteinsson, 2011; Hoeve et al., 2009)

\section{Parenting style across generation}

Do parenting styles remain same or change across generations? It may appear bizarre but there is empirical evidence to say that parenting styles change across different generations (Campbell \&Gilmore, 2007; Covell, Grusec, \&King, 1995). It is evident that parenting styles adopted by the parents also vary with generations. Research on intergenerational transmissions and continuity of parenting styles, behaviours and values within families in the past 75 years provides strong evidence that parenting styles change over time, even from generation to generation within families (Littlewood, 2009). As According to Driscoll, Russell \& Crockett (2008) permissive parenting has increased with generations while other parenting styles have declined. Sachdev and Misra, (2008) reported that parents of younger generation emphasized the emotional and psychological joys involved in parenting whereas the older parents mentioned the kin group benefits. Serbin and Karp (2003) opined that the intergenerational processes put families and children at risk for a broad variety of social, behavioral, and health problems. Convergent findings across a broad range of research populations in several countries, suggest that problematic parenting develops impart through learning the behavior modeled by one's own parents. A cross-sectional study was conducted by Kitamura, Ohashi, Murakami, and Goto (2014) found that in fathers and mothers, the correlation of the grandparents' perceived parenting styles were correlated with the current parenting styles reported by parents themselves greater than with the current parenting styles reported by spouse.

The above descriptions of studies provide contradictory patterns. In the western world there is evidence that parenting styles within families also vary across generations. However, the study 


\section{Parenting style: an Inter-Generational Study}

conducted on Jewish and Muslim mothers gave the opposite result as young mothers used to reproduce their parents' style (Pasternak, 2014). India also witnessed many historical changes in the past few decades such as massive urbanization, liberalization, entry of literacy rate, internet etc. There are studies to indicate that various historical changes such as massive urbanization, liberalization, entry of literacy rate, internet etc. would influence our behavior and also other social institutions such as family (Dalal\&Misra, 2002). The present study aimed at exploring do parenting styles has changed across generations in the Indian context? If yes then what are the ways in which it has changed.

In the present study the following hypothesis was formulated,

- The mothers of two generations in the same household differ in their parenting styles.

\section{METHOD}

In this study, concurrent mixed approach (Creswell, 2007) has used. Mixed method is that strategy of inquiry in which researcher uses both quantitative and qualitative measures. Concurrent mixed method can be explained as that where the researcher merges the quantitative and qualitative data through which a comprehensive analysis of the research problem can be carried out simultaneously.

\section{Participants}

In this study, for quantitative analysis, the sample comprised of 100 family units which consists of minimum two generation of mothers. The age range for, First generation of mothers were of the age group 50 years and above and, the second generation of mothers were of 30 years and above. The research participants were drawn from the middle class strata of Assamese society residing in Guwahati, Assam including the different religious groups such as Hindu, Muslims and Christians.

For qualitative analysis, 5 family units were contacted for a semi-structured interview. Therefore 5 mothers of first generation and 5 mothers of second generation participated in the interview residing in Guwahati, Assam.

\section{Measures}

Parental Authority Questionnaire (Buri, 1991) was used for measuring Baumrind's (1971) authoritarian, authoritative and permissive style of parenting. It consists of 30 items. There are two version of PAQ one for mothers and one for fathers. In this study only mother form was used. The scale contained 10 statements for each of the three types of parenting style. Test retest reliability over fortnight was found to be .81 for mother's permissiveness, .86 for mother's authoritarianism, and .78 for mother's authoritativeness.

For Qualitative analysis IPA (Interpretative phenomenological approach) was used. It is influenced by the theoretical traditions of phenomenology and hermeneutics. From 
phenomenology, IPA focuses on understanding the meaning of human experience. From hermeneutics IPA pays close attention to the interpretative activity involved in the analytical process when people are doing research with people. It is an idiographic method of inquiry (Rachel Shaw, 2011) IPA analysis was proceeded step by step .These are the steps: 1 . Writing descriptive summaries, 2. Making Initial interpretations, 3. Clustering themes, 4. Establishing the final theme, 5 . Writing up the analysis.

\section{Procedure:}

In this study, for quantitative data, The Parental Authority Questionnaire (Buri,1991) was given to two generation mothers to fill it as per the instructions given in the questionnaire. On the basis of scores of mothers they were assigned one of the groups of parenting style. Both the generation mothers were put in to authoritarian parenting style, authoritative parenting style and permissive parenting style.

For qualitative data, an interview was conducted on 5 mothers each of first and second generation. One question was put to the participants of older generation "How your parenting styles have changed as the children grew up?" And one question was put for the new generation participants "Whether she felt the need to change her parenting styles and if yes, in what ways?"

\section{RESULTS}

The results were analyzed by using Independent sample t-test.

Table, Mean, SD, t-values and Cohen's d of Old and New generation's mothers on Authoritarian, Authoritative and Permissive Parenting styles.

\begin{tabular}{|c|c|c|c|c|c|c|c|c|c|c|c|c|}
\hline \multirow[t]{2}{*}{ Groups } & \multicolumn{12}{|c|}{ Parenting style } \\
\hline & \multicolumn{4}{|c|}{ Authoritarian } & \multicolumn{4}{|c|}{ Authoritative } & \multicolumn{4}{|c|}{ Permissive } \\
\hline \multirow{2}{*}{$\begin{array}{l}\text { Old } \\
\text { Generation }\end{array}$} & mean & SD & $\mathrm{t}$ & $\mathrm{d}$ & mean & SD & $\mathrm{t}$ & $\mathrm{d}$ & Mean & SD & $\mathrm{t}$ & $\mathrm{d}$ \\
\hline & 32.92 & 6.24 & & & 34.88 & 4.98 & \multirow{3}{*}{-1.46} & \multirow{3}{*}{0.1} & 29.6 & 5.64 & \multirow{3}{*}{-1.62} & \multirow{3}{*}{0.1} \\
\hline & & & & & & & & & & & & \\
\hline $\begin{array}{l}\text { New } \\
\text { Generation }\end{array}$ & 30.13 & 6.17 & $3.07 *$ & 0.2 & 35.96 & 5.42 & & & 30.88 & 5.52 & & \\
\hline
\end{tabular}

The above table reveals that the mean value of the older generation's mothers on authoritarian parenting style is 32.92 , on authoritative parenting style is 34.88, on permissive parenting style is 29.6 and the mean value of the new generation's mother on authoritarian parenting style is 30.13 ,on authoritative parenting style is 35.96 ,on permissive parenting style is 30.88 which show that both the generation's mothers mostly used authoritative parenting style and after that the old generation's mothers practiced authoritarian parenting style and they least practice permissive 


\section{Parenting style: an Inter-Generational Study}

parenting style whereas we can say that the new generation mother's practiced permissive parenting style after authoritative parenting style and they least practiced authoritarian parenting style. Results of this study also revealed that mothers of old and new generation differ significantly on authoritarian parenting style, $\mathrm{t}=3.07 ; \mathrm{p}<.01$ and mothers of two generations did not significantly differ on authoritative and permissive parenting styles, $\mathrm{t}=-1.46 ;-1.62$ respectively. Even in case of authoritarian parenting style, the effect size is low. Thus, on the basis of this result we can say there is no substantial difference between the mothers of two generations across all three parenting styles.

\section{DISCUSSION}

The results presented above show that there is no substantial difference across two generations of mothers on the three parenting styles. Barnhart, Raval, Jansari, and Raval (2013) found that a majority of Indian and US college students selected the authoritative parenting as their own parenting styles and they were similar to their own parents. On the other hand, Driscoll, Russell \& Crockett (2008) have found that permissive parenting style has increased with generations while other parenting styles have declined. However, the present study suggests that mothers of both the generations have more preference for authoritative parenting style. The present results and the existing researches seem quite contradictory to each other. In order to fill this gap results from the IPA are presented below.

IPA resulted in the identification of four major themes namely, Factors influencing parenting styles; disciplinary strategies; warmth and nurturance; and communication style.

The first major theme is factors influencing parenting style and it comprises of three sub-themes, such as family type (nuclear family or extended family), parent's education, parent's own childhood experiences such as how they have been raised. Parenting style is influenced by family structure, in this way other family members such as in-laws etc influences the parenting styles. Changes in family contexts are likely to impact parenting practices (Durrant, 1996). As one of the interviewee of old generation has said that "Due to work overload she couldn't guide her children, and any decisions for her children was taken by her husband and in- laws and she always went with their decisions". This idea goes in line with the results of a national Zero to Three (2010) in which almost half of all parents said that they regularly turn to their mother or mother-in-law for information about child development and parenting. In the extended family system, close ties exist between husbands and their parents as well as other family members and husbands take most family decisions with their parents (Babalola, 1991). Roopnarine and Hossain (1992) found that joint family system greatly influences the socialization process of children. Other research studies also suggested that extended families support child rearing practices (Fapohunda and Todaro 1988; Isiugo-Abanihe, 1991). As the locale of the study was Assam, where joint family still exists therefore, the present result is in sync with the sociocultural reality of the participants. 


\section{Parenting style: an Inter-Generational Study}

Parent's own childhood experiences such as how they were raised was another factor which shaped the parenting styles of the young parents. One of new generation of parent has "blamed her parents for bringing her up in a very strict surrounding, but in her case she gives full freedom to her children and supports them in every aspect of life". This sub-theme goes in contrast with the findings of Zero to Three (2010) which stated that 53\% parents say their parents raised them has a major influence on their approach to parenting. Similarly, Barnhart, Raval, Jansari \& Rval (2013) indicated that parenting styles are most reflective of their own parents. There are various factors due to which, parents of different generation use opposite parenting styles than their own parents such as learning, influence of western culture and family structure. It can be explained through the principles of vicarious learning of social learning theory (Bandura, 1971). As parents have observed their own parents' parenting style and they have experienced its consequences on themselves and may not be happy the way they have been raised so on the basis of their own experiences they may want to use different parenting styles than their own parents.

Parents of new generation seem to be more influenced by western culture so they may also want to practice authoritative or permissive parenting styles. In India, over the years family structure has changed as nowadays most families are nuclear and in many homes both the parents are working and may have less time to spend with their children as compared to the old generation mothers. Hence the focus of the new parents would be to spend the quality time with their children thus imposing less strict rules or punished them and try to be more responsive and less demanding.

Like many other previous studies we too found that there is a relationship between parent's education and how they raise their children. As one of the respondent of old generation said " $I$ was not literate and I don't usually interfere in my daughter's matter whatever decided by my husband I agreed with him." Durrant (1996) found that parent's education affects parenting style as less-educated parents use higher levels of punishment in their parenting practices. A study on the acceptability of physical punishment of children in 14 countries found that higher levels of acceptability was reported higher among men, older parents and less educated parents (Gracia and Herrero, 2008). However, the link between parent's education and punishment is not always so straight (Dietz, 2000). As one of the interviewee from old generation said that "she is not very educated but she very well knows how to bring up her children."

Second major theme which has identified in this study is disciplinary strategies, which comprises of four sub-themes viz, usage and avoidance of punishment; rules and regulations regarding desirable behavior; and reasoning.

Parents use different disciplinary strategies to make their parenting more effective and to make children internalize social expectations, responsibilities and standard. Through discipline parents teach children the normative behaviors and values of society (Wissow, 2002). Some parents use 


\section{Parenting style: an Inter-Generational Study}

punishment, some avoid punishment, some make strict rules and some parents use reasoning, that is also known as inductive disciplinary strategy.

Two interviewee of new generation said that "I used to punish children if it is necessary to punish them" and "she uses verbal punishment" and three interviewees from old generation also said that they use punishment: "If her children are disobeying or misbehaving, she punishes them and punishment is necessary for children"; "she gives punishment when her children misbehave."

Some parents avoid punishment. Four participants from new generation express that they avoid punishment. According to one, "punishment is not the right way to show children the right path"; "at times when the child is not obeying I make her understand and avoid physical punishment"; "I don't believe in giving punishment to children"; "parents should not enforce punishment on children" whereas only one interviewee from old generation was against punishment as she said "she doesn't mostly prefer punishment". On the basis of this difference, it may be concluded that parenting style is changing over times in terms of punishment. There is a clear pattern which shows that old generation of parents use punishment quite often as compared to new generation of parents. With the increasing modernization Indians also make changes in their parenting, including the development of more individualistic values (Amin and Power, 2002). Mothers on who parents applied physical punishments were less likely to respond aggressively with their children (Park, 2001). On the other hand, some research findings suggest that parents who were themselves physically punished as children or adolescents are most likely to use physical punishment with their own children (Brower-russa et al, 2001; Ghate et al, 2003). Although some studies reported conflicting results, the pattern is largely that young generation uses less punishment than older generation of parents.

Strict rules and regulations for desired behavior is the next subtheme that emerged in the present study. Both of the generations' parents of this study said they use strict rules as disciplinary tactic. As one interviewee of new generation said that "I give proper warnings and instruction" and from old generation two interviewees said that "they practiced very strict rules and regulation to bring up their daughter" and "one of them believed that it is necessary to imposed strict rules and regulation on the children". It depends on parent's own experiences of childhood as findings of Kendler (1996) longitudinal twin study across several generations suggested that parental attitudes are derived from their own family of origin. Parent's own experiences of discipline in childhood can also shape their own parenting style (Bugental and Happaney, 2002). In India/Asian context, strict disciplining is the norms to raise children in contrast to the western world. Various research studies found that Asian Indian parents discourage autonomy, and emphasize the importance of obedience of elders (Dasgupta, 1989; Helwig \& Helwig, 1980; Wakil et al. 1981). Jambunathan and Counselman (2002) found that Indian mothers were more likely to use authoritarian parenting and corporal punishment, whereas Indian immigrant mothers in the United States were most likely to report authoritative parenting. In comparison to white 


\section{Parenting style: an Inter-Generational Study}

American parents, Asian American parents are more likely to be strict. This strictness in their parenting style reflects their belief that it is the core of parenting (Russell, Crockett \& Chao, 2010) in the Asian context.

Reasoning is a type of inductive discipline through which parents give explanation of their decisions to their children in order to make them understand their decisions. Inductive discipline promotes internalization of social and moral values in children (Kerr, et al. 2004). This study revealed that they use reasoning as disciplinary strategy, as two interviewees of new generation revealed their support to reasoning that "I make them understand everything politely and tell happenings and miss happenings of everything to my children"; "at times when the child is not obeying she makes her understand". And three participants of old generation said that "she makes her children understand by reasoning them"; "make children understand by giving appropriate reasons"; "she makes her daughter understand very politely with reasoning”. It can thus be said that reasoning as a method of parenting practices is common across both the generations of parents. This result is in contrast with the previous research findings which indicated that in western cultures (individualistic culture) authoritative parenting is more common and in eastern cultures (collectivist culture), authoritarian parenting is most common (Garg et al., 2005; Jambunathan \& Counselman, 2002). As reasoning is also a characteristic of authoritative parenting which needs to be explored further.

Warmth and nurturance was another theme that emerged in the present study and Support, freedom, reasoning, empathy and understanding were its sub themes. Warmth and nurturance among parents is related to parental expression of love, affection, support, understanding, approval and protection of child's physical and emotional well-being. According to Baumrind, (1991) warmth and nurturance is a key characteristic of authoritarian and permissive parenting. In this study new generation's parents has found to be more supportive and they support their children's freedom and independence as four interviewees from new generation revealed that, " $I$ gave full support and help to them"; "I am always with them"; "I allowed my daughter to do whatever she want to do and I support her"; "she gives her children full freedom and support them" and they also believe in making their children independent as "I allow my children to do what they want to do", "I allowed my daughter to do whatever she wants to do", "she gives her children full freedom", and "she gives full freedom to her children". This may be contrasted from the fact that none of the mothers of the older generation spoke about this.

Empathy means understanding a person from his/her frame of reference. Here, Parents from both the generations show empathy and understanding towards their children. Two interviewees of each generation said that "she understands her children very well as she too passed through those stages"; and "she understands her children"; "we should try to understand our children" and "we too understand our children". 
The fourth and last theme emerged is communication style that includes responsive; demanding but not responsive and use of reasoning as its sub-themes.

Parents use different communication style with their children. According to this study, new generation's parents were more responsive and less demanding than older generations parents as Parents of new generation said that "I believed that parents should allow their children to take their decision to some extent and do not enforced punishment on them", I gave full freedom to her children and supports them in every aspect of life"; "I make them understand everything politely"; "I gave full support and help to them". And two interviewees of old generation revealed that "she practiced very strict rules and regulation to bring up her daughter" and "she believed that it is necessary to imposed strict rules and regulation for children" that is showing their more demanding and less responsive attitude towards their children. But at the same time it became clear through the interview excerpts that older generation parents use more reasoning in their communication than new generational parents. As three participants of old generation said that "She makes her children understand by reasoning them"; "make children understand by giving appropriate reasons"; "she makes her daughter understand very politely with reasoning”.

\section{CONCLUSION}

Through mixed approach, this study revealed that parenting style passes from generation to generation to some extent and over the times it has changed as well. As the quantitative data suggests that mothers of both the generations prefer authoritative parenting style but through qualitative data, we have also found some similarities and differences in two generation's parents. As both the generation's mothers expressed that they use and avoid punishment, use strict rules and regulations, reasoning, and they show understanding towards their children. But new generation's mothers found to be more responsive, supportive and they help their children to be independent whereas older generation parents found to be stricter than new generation's parents as they more frequently use punishment, strict rules and regulations, more demanding and less responsive.

\section{REFERENCES}

Adalbjarnardottir, S. \& Hafsteinsson, L.G. (2001). Adolescents’ perceived parenting styles and their substance use: Concurrent and longitudinal analyses. Journal of Adolescence. 11, 401-423.

Amin.P., \& Power, T. (2002). Modernity and childrearing in families of Gujarati Indian adolescents. International Journal of Psychology, 37(4), 239-245.

Babalola, Stella. (1991). The Educated Wife and Decision Making: The Study of a Professional Group. LASU Journal of Humanities, 2, 1 \& 2:132-142.

Bandura, A. (1971). Vicarious and self-reinforcement processes. In R. Glaser (Ed.), The nature of reinforcement (pp. 228-278). New York: Academic Press. (Reprinted in, M. J. 


\section{Parenting style: an Inter-Generational Study}

Mahoney \& C. E. Thoresen [Eds.], Self-control: Power to the person. Monterey, CA: Brooks/Cole, 1974.)

Barnhart, C. M., Raval, V. V., Jansari, A., \& Raval, P. H. (2013). Perceptions of parenting style among college students in India and the United States. Journal of Child and Family Studies, 22 (5), 684-693.

Baumrind, D. (1967). Child care practices anteceding three patterns of preschool behavior. Genetic Psychology Monographs, 75(1), 43-8

Baumrind, D. (1971). Current patterns of parental authority. Developmental Psychology Monograph, 4, (1, Pt.2).

Baumrind, D. (1991). Parenting styles and adolescent development. In R. M. Lerner, AC. Peterson, \& J. Brooks-Gunn, (Eds.). Encyclopedia of adolescence, 2: 746-758. New York.

Berger,Ks.(2001).The Developing Person Throughout the Lifespan, New York;Springer-Verlag. Bhargava, M \& Aurora, S. (2001). Parental Behaviour. Agra : Rakhi publication.

Bower-Russa, M.E., Knutson, J.F. \& Winebarger, A. (2001). Disciplinary history, adult disciplinary attitudes and risk for abusive parenting. Journal of Community Psychology, 29, 219-40.

Bowman, M. A., Prelow, H. M., \& Weaver, S. R. (2007). Parenting behaviors, association with deviant peers, and delinquency in African American adolescents: A mediated-moderation model. Journal of Youth and Adolescence, 36(4), 517-527.

Bugental, D.B. \& Happaney, K. (2002). Parental Attributions. In: M.H. Bornstein (ed.),Handbook of Parenting. Volume 3: Being and Becoming a Parent (2nd edition). Mahwah, NJ: Lawrence Erlbaum Associates, pp. 509-35

Buri, J. R. (1991). Parental Authority Questionnaire. Journal of Personality Assessment, 57(1), 110-119.

Campbell, J., \& Gilmore, L. (2007). Intergenerational continuities and discontinuities in parenting styles. Australian Journal of Psychology, 59, 140-150.

Collins, A. W. et al.(2000) "Contemporary Research on Parenting," American Psychologist 55,218-32.

Covell, K., Grusec, J.E., and King, G. (1995). The intergenerational transmission of maternal discipline and standards for behavior. Social Development, 4, 32-43.

Creswell, J.W., \& Plano Clark, V.L. (2007). Designing and conducting mixed methodsresearch. Thousand Oaks, CA: Sage

Dalal \& Misra (2002). New Directions in Indian Psychology (vol. 1) Social Psychology. Sage India.

Dasgupta, S.S., (1989). On the trail of an uncertain dream: Indian immigrant experiences in America. New York: AMS.

Dietz, T.L. (2000). Disciplining Children: Characteristics associated with the use of corporal punishment. Child Abuse and Neglect, 24 (12), 1529-42.

Driscoll, A. K., Russell, S. T., Crockett, L. J. (2008). Parenting styles and youth well-being across immigrant generations. Journal of Family Issues, 29, 185-209. 


\section{Parenting style: an Inter-Generational Study}

Durrant, J. (1996). The Swedish Ban on Corporal Punishment: Its history and effects. In: D. Frehesse, W. Horn and K.-D Bussman (eds.), Family Violence against Children: A Challenge for Society. New York: Walter de Gruyter, pp. 19-25.

Fapounda, R. Eleamor, Todaro, P. Michael. (1988). Family structure, implicit contracts, and the demand for children in Southern Nigeria. Population and Development Review, 14, 4: $571-594$.

Garg, R., Levin, E., Urajnik, D., \& Kauppi, C. (2005). Parenting style and academic achievement for East Indian and Canadian adolescents. Journal of Comparative Family Studies, 36, 653-661.

Ghate, D., Hazel, N., Creighton, S., Finch, S. and Field, J. (2003). The National Study of Parents, Children and Discipline in Britain. London: Policy Research Bureau.

Gracia, E., \& Herrero, J. (2008). Is it considered violence? The acceptability of physical punishment of children in Europe. Journal of Marriage and Family, 70, 210-217

Helwig, A.W., \& Helwig, U.M. (1980). An immigrant success story: East Indians in America. Philadelphia: University of Pennsylvania Press.

Hoeve, M.; Dubas, J.S.; Eichelsheim, V.I.; van der Laan, P.H.; Smeenk, W.; Gerris, J.R. (2009). The relationship between parenting and delinquency. Journal of Abnormal \& Child Psychology. 37, 749-775. 21.

Isiugo-Abanihe, Uche C. (1991). Parenthood in Sub-Saharan Africa: Child fostering and its Relationship with Fertility. In Locoh, T., Hertrich, V., editors. The onset of fertility transition in Sub-Saharan Africa. Belgium: Derouaux Ordina Editions: 163-174.

Jambunathan, S., \& Counselman, K.P. (2002). Parenting attitudes of Asian Indian mothers living in the United States and in India. Early Child Development and Care, 172, 657-662.

Kendler, K.S. (1996). Parenting: A Genetic-Epidemiologic Perspective. American Journal of Psychiatry, 153,11-20.

Kerr, D., Lopez, N., Olson, S. \& Sameroff, J. (2004). Parental discipline and externalizing behaviour problems in early childhood: The roles of moral regulation and child gender. Journal of Abnormal Child Psychology, 32 (4), 369-83.

Kitamura.T., Ohashi. Y., Murakami.M., \& Goto. Y. (2014). The mediation of parental personality on preschool children's temperament by parenting styles. American Journal of Psychology and Behavioral Sciences. 1(3): 21-28.

Littlewood, M. F. (2009). Parenting styles and values: Mechanisms of intergenerational continuity and discontinuity. M.A. thesis. Western Carolina University.

Luyckx, K.; Tildeley, E.A.; Soenens, B.; Andrews, J.A.; Hampson, S.E.; Peterson, M.; Duriez, B. (2011).Parenting and trajectories of children's maladaptive behaviors: A 12-year prospective community study. Journal of Clinical and Child Adolescence. Psychology 40, 468-478, doi:10.1080/15374416.2011.563470.

Maccoby, E. E., \& Martin, J. A. (1983). Socialization in the context of the family: Parent-child interaction. Handbook of child psychology, 4, 1-101.

Park, M.S. (2001). The factors of child physical abuse in Korean immigrant families. Child Abuse and Neglect, 25, 945-58. 
Pasternak, R. (2014). Intergenerational Transmission of Parenting Style Among Jewish and Arab Mothers in Israel. Childhood Education, 90, 2.

Roopnarine, J. L., and Hossain, Z. (1992). Parent-child interactions in urban Indian families in New Delhi: Are they changing? Pp. 1-16 . Roopnarine, \& Carter, D. B. (eds.), Annual Advances in Applied Developmental Psychology, 5, 1-17. New Jersey: Ablex Publishing Corporation.

Russell, S., Crockett, L. \& Chao, R. (2010). Asian American parenting and parent-adolescent relationships. Springer Science + Business Media. New York.

Sachdeva, N. \& Mishra, G. (2008). The changing images of parenting in the three subcultures of India. Journal of the Indian Academy of Applied Psychology, 34, 16-23

Serbin, L., \& Karp, J. (2003). Intergenerational studies of parenting and the transfer of risk from parent to child.Current Directions in Psychological Science, 12, 138 -142.

Shaw, R.L. (2011). Celebrating the achievements and preparing for the challenges ahead in IPA research. Invited commentary. Health Psychology Review, 5(1), 2833..DOI:10.1080/17437199.2010.524808

Steinberg, L. (1996). Beyond the Classroom; Why School Reform Has Failed and What Parents Need To Do. New York.

Wakil, S.P., Siddique, C.M., \& Wakil, F.A. (1981). Between two cultures: A study of socialization of children of immigrants. Journal of Marriage and the Family, 43, 929940.

Wissow, L.S. (2002). Child Discipline in the First Three Years of Life. In: N. Halfon, K.T. McLearn and M.A. Schuster (eds.), Child-rearing in America: Challenges facing parents with young children. New York: Cambridge University Press, pp. 146-77

Zero to Three (2010). Grandmother knows best- new parent survey reveals family, upbringing and faith are most critical influences on child rearing. Retrieved from www.zerotothree.org/about-us/funded-projects/parenting-resources/very, final surveypress release 3-323 pdf. 